\title{
La narrativa histórica de José Carlos Mariátegui: la construcción de una subjetividad revolucionaria en los Andes peruanos
}

\author{
Miguel Ángel NACIÓN PANTIGOSO
}

\begin{abstract}
RESUMEN
A finales del siglo XIX e inicios del XX en el Perú se desarrollaba un debate respecto de qué Estado podía levantarse sobre la base de la sociedad peruana. En este sentido, fue imprescindible conocer las características de la sociedad. Las emergentes y noveles ciencias sociales asumieron esta tarea. Sin embargo, la construcción del Estado-nación peruano exigía una mirada de conjunto, es decir una narrativa del derrotero que ha seguido y seguirá la comunidad. Es en este punto en el que las narrativas históricas toman un papel central en la proyección de una nacionalidad. José Carlos Mariátegui participó en la elaboración de una narrativa histórica de carácter moderno para el Perú. En este texto sostenemos que hay dos conceptos que articulan la narrativa mariateguiana de la historia: el indio y el mito. Ambos conceptos se articulan mediados por el marxismo construyendo así una subjetividad revolucionaria como factor de concreción de la nación peruana.
\end{abstract}

PALABRAS CLAVE: Estado-nación, historia, positivismo, espiritualismo, marxismo, mito, indio

\section{The historical narrative of Jose Carlos Mariategui: The construction of a revolutionary subjectivity in the Peruvian Andes}

\section{ABSTRACT}

Between the end of the nineteenth century and first decades of twentieth century, the Peruvian intelligentsia discussed what State the Peruvian society required. The question was faced with the help of the modern social sciences like sociology and scientific history. However, the building of Nation-State required a view of the society like totality. This means a history about the past, the present and future. José Carlos Mariátegui made a modern narrative about the Peruvian Nation-State disagreeing with consolidated narrative, i.e. positivist narrative and spiritualist narrative. Mariátegui's narrative was articulated by two principles or central concepts: myth and indio. These concepts together with a Marxist framework built the modern narrative of Peruvian society and the revolutionary subject of Peruvian history.

KEYWORDS: Nation-state, history, positivism, spiritualism, Marxism, myth, indio. 


\section{Introducción}

¿Podemos encontrar en José Carlos Mariátegui elementos para la crítica del eurocentrismo, para pensar en modernidades alternativas, o elementos para decolonizar el discurso de la revolución? Estas preguntas nos invitan a buscar elementos teóricos dentro de nuestra tradición ideológica de cara a enfrentar la crítica de la modernidad desde posiciones poscoloniales. El papel que Mariátegui juega en este sentido resulta por lo demás crucial, porque su trabajo teórico no significó el rechazo del horizonte emancipador de la modernidad para apostar por un indigenismo esencialista y contrario a lo occidental. Antes de esto, su objetivo teórico fue el de articular el discurso emancipador con la experiencia histórica peruana. En este sentido, existe en Mariátegui una efectiva apuesta por entender la modernidad en un sentido diverso.

Situados en el contexto de los últimos años del siglo XIX, en la etapa de postguerra con Chile, destacamos la renovación del campo cultural en el Perú. Augusto Salazar Bondy señala que este proceso se da con el positivismo y las diversas corrientes cientificistas decimonónicas. Entre los autores leídos se encuentran Auguste Comte, Hyppolite Taine, Gustave Le Bon, Herbert Spencer. Antes de terminar el siglo se sumará al positivismo las corrientes espiritualistas influenciadas por Henri Bergson. Esta confluencia de ideas nuevas alimenta debates respecto de las ciencias sociales, la filosofía y de la sociedad peruana. Así, se plantean tesis que discuten el porvenir de la sociedad: ¿cuál es el mejor régimen de gobierno?, ¿qué orden moral debemos buscar?, y ¿cuál es la relación entre naturaleza y voluntad?

De forma paralela se produce el establecimiento del horizonte de sentido de la modernidad. Aquí es significativo el contexto de la postguerra con Chile, ya que da el marco de fondo que hace inteligible la crítica al pasado. En los esfuerzos por explicar las causas de la derrota, los intelectuales de la reconstrucción elaboran un sentido de emancipación frente a lo que se consideraba las trabas al proyecto republicano. Figuras de posiciones opuestas como Manuel González Prada y Javier Prado y Ugarteche comparten este horizonte. Las nuevas corrientes filosóficas darán forma a este horizonte crítico moderno frente a la historia y a la política.

En el presente trabajo abordamos el posicionamiento ideológico de Mariátegui. Es decir, su posicionamiento crítico frente a las visiones naturalistas y espiritualistas de la historia. La tesis que sostenemos es que la crítica de Mariátegui consiste en el rechazo del eurocentrismo característico a estas dos visiones, el cual se expresa en una episteme marxista de la historia peruana que se articula a través de dos significantes: indio y mito.

\section{6/REEVISTA de SOCOLOOGíA 26}




\section{Eurocentrismo}

El fundamento del eurocentrismo se encuentra en la metafísica moderna. En el siglo XVII se inicia la conceptualización de la humanidad. Descartes pone las bases con el res cogitans o cosa pensante por la cual lo humano es pensamiento que se expresa por las facultades psicológicas tales como la imaginación, la memoria, el deseo o el juicio. De este modo, lo humano se constituye en un sujeto frente a un objeto: el mundo o "res extensa". Por otro lado, la objetivación del mundo histórico pasa por expresar las leyes que rigen la voluntad. En este sentido, las filosofías de la historia buscan dar cuenta del proceso fenoménico por el cual la voluntad del sujeto metafísico se expresa y se realiza conforme a su propia ley. El caso paradigmático de esto es Hegel, para él la objetivación de la historia se funda en la facultad que tiene el Espíritu de ponerse a sí mismo como objeto permitiéndose conocerse a sí a través de fenómenos sociales. En el marco de la fenomenología hegeliana la historia tiene un sentido: la realización de la libertad, la cual es entendida como la facultad de autodeterminación que está expresada concretamente en la sociedad civil europea. Así pues, sea el caso del sujeto pensante o en el de la voluntad, estamos ante un vaciamiento del significado cultural o de la experiencia histórica. Por tanto, estamos ante categorías abstractas que ocultan la diferencia.

El eurocentrismo se funda en el sujeto vaciado culturalmente y se define como una perspectiva que subordina al otro-de-occidente. Se forma en el establecimiento de un horizonte de sentido legitimado como el único posible y válido dentro del marco de lo razonable. Aquí se constituye la identidad de lo occidental como sinónimo de civilización en oposición con la identidad subordinada del otro: el bárbaro. Sin embargo, esto no significa que el otro sea ontológicamente el otro de la civilización; sino más bien este es considerado lo mismo que su opuesto pero sin el mismo grado de autoconciencia. De este modo, el eurocentrismo niega la posibilidad y la legitimidad de una experiencia histórica diferente, ya que todas las culturas tienen la misma historia, a saber la de la autoconciencia.

El horizonte de sentido eurocéntrico forma una realidad social de subordinación: la colonialidad. Según Aníbal Quijano ella se caracteriza por la racialización de la sociedad, es decir, la categoría raza estructura las relaciones sociales, define las identidades y distribuye los recursos. De tal modo, se constituye en un concepto clave para entender el funcionamiento social. La colonialidad no es la realidad de las sociedades poscolonial, sino más bien es la característica de la sociedad global que nace con la conquista de América y se consolida con el capitalismo global. Debido a esto, Quijano y otros han reconocido que la colonialidad nace con la modernidad misma, es decir que a la par que se producían los procesos de racionalización, espe- 
cialización y secularización de los distintos campos sociales; también las identidades se racializaban y se consolidaban formas de dominación como el racismo. Así pues, la colonialidad es la cara oculta de la modernidad, ambas posibles por el eurocentrismo.

\section{El deseo de la república}

Mark Thurner toma a Jacques Rancière para afirmar que la escritura de la historia es un acto poiético; es decir un acto creador de un sujeto ahí donde antes no había subjetividad, o no existía una realidad de sentido. La historia nos muestra a este nuevo sujeto como una continuidad temporal que se entreteje en el pasado, el presente y el futuro. Lo característico de escribir historia no es el darle un sentido lineal o de progreso a la subjetividad, sino más bien definirla siempre como algo inacabado que aspira a la realización; a saber, una realidad deseante (Thurner, 2012).

En la historiografía encontramos a los autores de este acto poiético, los cuales aparecen desde la temprana colonia. Sin embargo, vamos a enfocarnos en una forma determinada del deseo llamado Perú, la que comenzó a constituirse durante el siglo XIX: la república. Jorge Basadre ha logrado expresarla de la mejor forma con el nombre de promesa. A la pregunta: ¿para qué se fundó la república? Basadre responde para cumplir en ella su promesa, esto es crear una sociedad de orden y prosperidad; de bienestar y riqueza. La realización de una vida, sana próspera, fuerte y feliz; lo que aún no se ha podido cumplir en el tiempo que tenemos de vida republicana (Thurner, 2012). El deseo de la república aspira a cumplir una promesa que se fue forjando en las distintas etapas de la vida peruana: imperio incaico y colonia pero que solo los hijos de la república pueden realizar. Estos reciben el legado del tiempo para enfrentar la tarea de construir lo que aún no existe, para hacer realidad el deseo llamado Perú.

La creación del sujeto llamado Perú plantea un problema: la pregunta por su identidad. En la definición de quienes somos, los intelectuales, en sentido amplio, como agentes hábiles en el uso de los recursos simbólicos, han tratado de delinear la sustancia cultural de la identidad peruana. Su papel principal ha sido el de crear una tradición nacional; es decir, ordenar la materia bruta del pasado, constituyendo así un horizonte comprensivo. En este alcanzamos la significación y el entendimiento de nuestro pasado para que nuestro futuro tenga sentido. En la tradición nacional el deseo de la historia toma forma constituyéndose como horizonte de sentido (Sanders, 1997).

La creación de la tradición republicana en el Perú se ha caracterizado por la tensión entre lo criollo e indígena. Karen Sanders señala que ella se basa en el problema

\section{8/ RELUSTA DE SOCOLOOGÍA 26}


político de asumir a los indígenas como actores nacionales. El peligro radicaba en que las elites indígenas tenían un dominio territorial y un peso político considerable sobre la población indígena, pero sobretodo, tenían una tradición desde la cual podían legitimarse: el imperio de los incas, algo de lo que las elites criollas carecían. Además, la eventual dirección indígena de una revolución y de la construcción de un Estado significaba revivir los temores dejados por la revolución de Tupac Amaru II. Así pues, la tradición republicana creada por los criollos apeló a narraciones en donde lo indígena aparecía como algo residual. Exaltaba el pasado imperial pero el indígena del presente no podía ser parte de la república, sobre todo porque éste no tenía lugar dentro de una herencia occidental emparentada con las civilizaciones modernas (Méndez, 2000).

La tensión política entre lo criollo y lo indígena limitó la pluralidad cultural de las tradiciones nacionales, ya que implicó imaginar la nación dentro del horizonte de la historia universal. En la narrativa criolla de la historia lo indígena se ubicaba en el pasado: el imperio de los incas. De otro lado, el presente era el momento de los criollos, mientras que el futuro implicaba una tarea por realizar: la modernización social. De este modo, la narrativa de la historia republicana fue eurocéntrica, es decir se sustentó en el supuesto de una subjetividad que se construye en un sentido de progreso que va desde el pasado: lo indígena; hacia el futuro: la modernización u occidentalización. El eurocentrismo fue el velo político que ocultaba la peligrosa presencia de la diferencia cultural que significaba el indio.

\section{Los supuestos de la historia: evolución, organicismo, naturalismo}

De acuerdo con Augusto Salazar Bondy, el positivismo en el Perú significó la modernización de nuestro pensamiento de cara al contexto de la reconstrucción nacional postguerra con Chile. Antes del auge positivista de la última década del siglo XIX imperaba en el país una filosofía de carácter escolástico sostenido por la influencia de la iglesia sobre las principales instituciones educativas. Las corrientes positivistas quiebran esta hegemonía buscando poner las bases de la comprensión científica de la realidad. El sentido modernizador de esto se expresa en el compromiso con el desarrollo de los enfoques científicos en las ciencias sociales, el derecho y las ciencias médicas. De cara a una sociedad que veía con dudas las posibilidades de la república, el sentido político de esta modernización fue poner las bases teóricas para retomar la promesa republicana. Así pues, no es gratuito que el positivismo apareciera con un carácter liberal. Sus principales conceptos son la evolución y el carácter nacional, ambos guardan relación con una tradición naturalista asentada desde la colonia. 
Entre las principales fuentes del positivismo se encuentran Auguste Comte, Hyppolite Taine, Gustave Le Bon, Jean-Marie Guyau, y Herbert Spencer.Y entre los referentes del positivismo peruano tenemos a Javier Prado y Ugarteche, Clemente Palma, Manuel González Prada, Miguel H. Cornejo, entre otros.

Por su lado, el espiritualismo es la corriente que sigue al positivismo. Aparece en la crítica a las limitaciones deterministas y reduccionistas de la subjetividad de los enfoques positivistas. En este sentido, nos da categorías para pensar la libertad y desarrolla elementos para la crítica moral de la república. Su mejor exponente fue el filósofo Alejandro Deustua quien se convirtió en una influencia para filósofos posteriores como Mariano Iberico, Víctor Andrés Belaunde y Pedro Zulen. El espiritualismo incluye distintas corrientes entre ellas están la filosofía de Henri Bergson, el pragmatismo de William James y algunas otras formas de recuperación de la metafísica.

A pesar de que el positivismo y el espiritualismo eran posiciones enfrentadas respecto al conocimiento y a la moral' ambas perspectivas compartían un supuesto de fondo: el evolucionismo. Este concepto proveniente de la filosofía de Spencer planteaba que la naturaleza y la historia son una realidad orgánica que se desarrolla en el tiempo. En este proceso el más apto es seleccionado naturalmente al adaptarse a las nuevas condiciones que impone la evolución. Todos los cambios acontecidos en la naturaleza y en la historia se explican por la evolución, desde el origen de la vida hasta el comportamiento social. Los positivistas peruanos aceptaban la evolución por su adhesión a las ideas de Spencer, y los espiritualistas porque asumieron que la libertad es el resultado de la evolución psíquica. De este modo la subjetividad creadora se armoniza con la ley de la naturaleza.

El supuesto de la evolución empata bien con dos paradigmas coloniales que dan forma a los significados de nuestro mundo intersubjetivo: el organicismo y el naturalismo. De acuerdo con Miguel Marticorena (Ballón, 2011, 121-122), el organicismo es la metáfora social que compara al Estado o sociedad con un cuerpo viviente en donde los distintos grupos sociales ocupan un lugar y cumplen la función que le corresponde a tal lugar. La metáfora organicista está asociada directamente con la formación de identidades naturalizadas, es decir razas. Asimismo, Marticorena señala su presencia desde la colonia, en la fundación del Cusco (1534). También, ha estado presente a principios del siglo XIX en los proyectos separatistas durante la emancipación; $y$, además, en los años finiseculares de la postguerra con Chile, en las reflexiones de Manuel González Prada. De otro lado, el naturalismo es la forma por la cual se justifica el orden social, es decir se determinan identidades fijas cuyo fundamento es un factor natural, puede ser el clima, la sangre, o la geografía. Estas

1 El centificismo, la antimetafísica, y el determinismo naturalista positivistas colisionaban con la recuperación metafísica, el subjetivismo y el énfasis de la libertad del espiritualismo.

\section{0/ RELUSTA DESSOCOLOOGIA 26}


identidades toman forma en las distintas razas y estructuran una sociedad donde la movilidad social es sinónimo de caos. Al igual que el organicismo, el naturalismo data de la colonia y está presente en distintos momentos, llegando también al siglo XIX en los tratados del racismo científico. En suma, organicismo y naturalismo operantes en la intersubjetividad decimonónica funcionan como marco desde el cual el evolucionismo toma sentido. De esta forma se desarrolla una estrategia conceptual por la cual el cientificismo moderno es leído desde metáforas coloniales, una suerte de modernización tradicionalista.

\section{Los límites del horizonte político decimonónico}

El texto referente para los positivistas peruanos respecto de la justificación de la república fue el Estado social durante la dominación española (1890). Su autor es Javier Prado y Ugarteche y en él aplica el concepto de carácter nacional, el cual hacía referencia a la psicología de una colectividad. El estudio de Prado busca dar cuenta del carácter colectivo de la sociedad peruana a través de factores como el clima, la herencia genética, y el medio geográfico. A partir de estos datos se pueden explicar las virtudes y los vicios de las razas para determinar sus aptitudes en determinados sociedades o regímenes políticos. El texto de Prado cumple con esta tarea. Señala que de las razas que constituyeron el virreinato: indios, blancos, y negros; solo los criollos, los descendientes de los europeos, tienen el grado de moralidad necesario para formar una comunidad nacional, ya que las otras razas han entrado en un proceso de degradación inevitable. Sin embargo, la conclusión de Prado añade que la degradación de las razas, y en particular la indígena, se debe a las instituciones coloniales de gobierno, a saber las monárquicas. Así pues, las condiciones de posibilidad para la nación peruana solo pueden ser la república y una raza virtuosa, la cual podría alcanzarse a través de la educación y la inmigración (Rivera, 2012, 21-24)².

El concepto de carácter nacional, y las conclusiones del trabajo de Prado influyeron en el debate sobre las condiciones para la construcción de la nación, un tema sensible en el contexto de la postguerra con Chile. Ejemplo de esto fue la idea compartida de que el Perú debía construirse sobre la base del rechazo a la colonia. Los programas liberales dieron forma al anticolonialismo buscando una quiebra radical con las instituciones sociales de carácter colonial, a saber la iglesia y las costumbres religiosas. La

2 Por el propósito que busca, el texto de Javier Prado puede ser considerado una obra de filosofía política positivista. Así lo entendió José de la Riva Agüero quien enfrenta la posición liberal de Prado con su tesis el Carácter de la literatura independiente. En ella, al igual que Prado, da cuenta del carácter nacional pero a través de la literatura para reivindicar a la colonia. 
idea de fondo del anticolonialismo era la idea de progreso. La realización de la nación se encontraba en el horizonte del progreso, lo cual exigía eliminar todo aquello que se lo impidiera. Otro ejemplo de la influencia de las ideas de Prado fue la comunidad imaginada que proyectaba, a saber una comunidad apta para la civilización o racialmente homogénea. Esto significó plantearse el problema de las razas en el Perú, es decir cómo enfrentar la diversidad cultural. Dentro de una perspectiva evolucionista, las demás razas no pueden ser integradas al progreso a menos que sea en términos de subordinación, en el mejor de los casos. En el peor, se considera la asimilación un riesgo para alcanzar el progreso, por lo cual lo único que se puede hacer con ellas es el exterminio. En suma, si buscamos el progreso, es necesaria la homogeneización cultural, es decir convertirnos en una raza apta para la civilización. En este proyecto la diversidad de razas no tiene porvenir (Ávila, 2010, 73-96) ${ }^{3}$.

Las afirmaciones deterministas respecto del porvenir de la nación peruana no dejaban espacio para la voluntad. Los sociólogos positivistas apoyaban la firmeza de sus conclusiones sobre el necesario cumplimiento de las leyes psicológicas. Frente a esto, la crítica surgió para recuperar la libertad, la subjetividad de la conciencia (Sayán, 2003) ${ }^{4}$. Esta fue la bandera del espiritualismo peruano y tuvo como su mejor exponente a Alejandro Deustua. Sobre la base de una metafísica de corte especulativo, en donde la conciencia recupera su capacidad creadora de la experiencia, Deustua ofrece elementos para una crítica del marco naturalista. En este sentido, afirma que nuestras posibilidades de convertirnos en una comunidad no dependen exclusivamente del porvenir de las razas, ya que existe un factor central no considerado por los sociólogos: la moralidad como efecto de la libertad. Así pues, el problema radica en el tipo de moralidad imperante en la sociedad, por lo mismo la solución pasa por una transformación moral del País. La forma política y ética que toma la crítica de Deustua es la de su propuesta pedagógica, en donde el valor tiene una posición central, ya que funciona como la guía, el ideal orientador de la subjetividad. El horizonte hacia el cual la reforma axiológica y de la cultura peruana debe orientarnos es el de la solidaridad. De este modo Deustua abre el camino para considerar el potencial transformador de la acción de los sujetos sustentado en la fuerza de la libertad.

La comprensión positivista y espiritualista de la historia de la nación peruana tiene un sentido: el progreso, es decir realizar la promesa republicana. Tanto Javier Prado como Alejandro Deustua son filós ofos liberales. Sin embargo, las condiciones fácticas del país

3 La referencia es a la tesis de licenciatura de Clemente Palma: El porvenir de las razas en el Perú. Este texto es una obra de sociología positiva, en donde se llega a estas conclusiones.

4 El concepto de libertad en Alejandro Deustua debe ser entendido desde el marco filosófico de Henri Bergson, en donde la libertad es entendida en términos psíquicos como duración, estados de la consciencia articulados en los cuales ella se reconoce como una sola y a partir de la cual ella ejerce su capacidad creadora de sí misma y de su experiencia. Así pues, el sentido pleno de la libertad es creador, de orden estético.

\section{2/ REEUSTA DE SOCOOLOGíA 26}


cuestionaban las posibilidades reales de entrar en la senda del provenir. El problema principal fue la diversidad cultural y material del Perú. A los ojos de positivistas y espiritualistas esto se evidenciaba en la poca habilidad de algunas razas para adaptarse a la civilización. Sea por razones naturales o debido a que la evolución no operó en ellas el grado de conciencia para la libertad, en cualquier caso, ellas no podían ser parte de la nación por venir. De este modo, los pensadores liberales de ambas corrientes se encontraron en una contradicción ${ }^{5}$ : proclamar el horizonte republicano pero a la vez negar la condición de ciudadanos a los sectores étnicamente diferentes. Las metáforas sociales que expresan esta contradicción son la república sin ciudadanos y la república aristocrática. Ambas expresan los límites del horizonte político del positivismo y el espiritualismo, a saber una república excluyente y autoritaria.

\section{El marxismo de Mariátegui: método y mito}

El contexto de José Carlos Mariátegui es diferente del vivido por los intelectuales de la postguerra con Chile. Positivistas y espiritualistas vivieron en una sociedad preindustrial estructurada por las relaciones precapitalistas, es decir en donde la acumulación de riqueza se basaba en el control de la fuerza de trabajo y de la tierra, y no en la circulación libre de mercancías. Asimismo, estas relaciones se vieron reforzadas por el capital comercial internacional en la medida que éste las utilizaba dentro de un circuito de producción de bienes internacional cuyo centro de acumulación se encontraba en los países industrializados. El siglo XIX es el escenario de la configuración de un sistema económico dependiente que limita la formación de un mercado interno y de una burguesía industrial, lo que en términos políticos significó el fortalecimiento de los terratenientes. Sin embargo, esta situación cambió drásticamente en el tránsito al siglo XX. La posguerra con Chile había llevado a la bancarrota al Estado quien entregó los medios productivos al capital extranjero al mismo tiempo que facilitó su ingreso y su acción sobre los espacios productivos. Así pues, durante las dos primeras décadas del siglo XX tenemos la modernización del país por efecto del capitalismo internacional. Esta modernización consistió en las transformaciones que impuso al aparato productivo, al mercado interno, a la estructura de clases y al Estado en beneficio de su modelo de acumulación: el enclave. En este sentido, la modernización no apuntó a la formación de una sociedad de mercado interno sustentada en la producción y

5 La operación conceptual que procesa esta contradicción puede ser comprendida desde lo que Fernando de Trazegnies ha definido como modernización tradicionalista. Véase. Trazegnies, Fernando. La genealogía del derecho peruano los juegos de trueques y préstamos. En: Adrianzén, Alberto. Pensamiento político peruano. Lima: DESCO. Centro de Estudios y Promoción del Desarrollo. 1987, 99-134. 
venta de mercancías, sino a hacer los cambios necesarios para asegurar el interés de las nuevas metrópolis económicas. Esto implicó una alianza con aquellos que controlaban la fuerza de trabajo y los territorios con el fin de garantizar el desarrollo del capital internacional. De este modo, la modernización capitalista se basó en las relaciones precapitalistas de la sociedad peruana, además de fortalecerlas. Este fue el contexto que vivió Mariátegui.

En lo que respecta al ámbito intelectual se dio un acontecimiento importante: el arribo del pragmatismo. Esta corriente filosófica apareció en el medio local como una forma de crítica al positivismo pero también como una crítica al espiritualismo de origen bergsoniano. Su representante en el Perú fue Pedro Zulen. Su crítica consiste en discutir el supuesto de una conciencia contemplativa frente a la realidad. En efecto, Zulen apuesta por una subjetividad que va más allá de ser mera consciencia. Además, problematiza la naturaleza de la realidad discutiendo el papel de la acción en su constitución. Este trabajo es central para entender el concepto de historia en Mariátegui.

La historia marxista que inicia Mariátegui es una crítica a la idea de ciencia positiva, es decir una crítica al conocimiento como descubrimiento de las leyes que gobiernan la realidad, en el caso de la historia a la búsqueda leyes de la evolución. Para Mariátegui el marxismo basa su cientificidad en ser un método para interpretar la realidad y no en ser un corpus de leyes apriorísticas. De este modo supera el dualismo sujeto-objeto para afirmar una primacía subjetiva, es decir deviene en una ciencia de la realidad espiritual. Esta perspectiva de ciencia le permite a Mariátegui desligarse de otra característica cara al positivismo y espiritualismo: la idea de evolución. En efecto, en una realidad subjetiva el progreso lineal no es necesario, por tanto la ciencia histórica no está destinada a determinar sus leyes. En contraste, la historia da cuenta de rupturas, eventos que rompen la continuidad del tiempo dando paso a nuevas épocas. Este es la historia que expone en los 7 ensayos de interpretación de la realidad peruana. Aquí el inicio del Perú moderno es resultado de una ruptura cuyo significado no es económico sino político y militar.

Hasta la Conquista se desenvolvió una economía que se desenvolvía libre y espontáneamente del suelo y la gente peruana (...).

Los conquistadores españoles destruyeron, sin poder naturalmente reemplazarla, esta formidable máquina de producción. La sociedad indígena, la economía inkaica, se descompusieron y anonadaron completamente al golpe de la Conquista. Rotos los vínculos de su unidad, la nación se disolvió en comunidades dispersas (...).

El virreinato señala el comienzo del difícil y complejo proceso de formación de una nueva economía (Mariátegui, 7 ensayos de interpretación de la realidad peruana, 1999, 13-14).

\section{4/ REEUSTA DE SOCOOLOGÍA 26}


En el marco de un marxismo como método interpretativo, Mariátegui puede plantear una historia del Perú y con él de Latinoamérica, es decir puede comprenderlos desde los agentes que juegan dentro del espacio local y que constituyen la objetividad social. De este modo, según Antonio Melis, sitúa los rasgos específicos de una formación económica social en un modelo de desarrollo histórico (Quijano, 2007). Además, a partir de su método, Mariátegui puede salir al encuentro de la historia de la colonización de la periferia y del avance imperialista del capital sobre ella sin renunciar a la mirada global de la historia, que no es lo mismo que una historia universal ${ }^{6}$.

Las fases fundamentales de nuestra economía [... p pueden ser concretadas con los siguientes hechos:

1.- La aparición de la industria moderna (...) que transforma sobretodo la vida de la costa. La formación de un proletariado industrial (...).

2.- La función del capital financiero. El surgimiento de bancos nacionales que financian diversas empresas industriales y comerciales pero se mueven dentro de un ámbito estrecho, enfeudados a los intereses del capital extranjero y de la propiedad agraria.

3.- El acortamiento de las distancias entre el Perú y los Estados Unidos y Europa (...).

4.- La gradual superación del poder británico por el poder norteamericano (...).

5.- El desenvolvimiento de una clase capitalista, dentro de la cual cesa de prevalecer como antes la antigua aristocracia (...) (Mariátegui, 1999, 24-28).

En relación con el método de Mariátegui está su concepto de realidad histórica. Esta puede ser definida como praxis histórica. En tanto la objetividad social son las creencias y los valores realizados a través de la acción, ésta es cambiante, abierta a la crisis de ideales, su renovación, a su confirmación en la experiencia o a su rechazo. De este modo lo característico de la realidad social es el cambio, pero no dirigido por una lógica de progreso, la cual se sustenta en un a priori, sino más bien responde al horizonte de sentido de la acción, a aquello que tiene valor para el sujeto: un ideal, una fe, una ilusión. Así pues, la praxis histórica se desenvuelve por el propósito de realizar su ideal. Cada etapa histórica es el tiempo de un ideal.

El progreso - o el proceso humano — se cumple por etapas. Por consiguiente la humanidad tiene permanentemente la necesidad de sentirse próxima a una meta. La meta de hoy no será seguramente la meta de mañana; pero, para la teoría en marcha es la meta final. El mesiánico milenio no vendrá nunca. El hombre

6 Universal tiene el sentido de Hegel, es decir una voluntad metafísica que se despliega siguiendo etapas hasta alcanzar la autoconciencia, las cuales todas las culturas deben pasar en el proceso de evolución o progreso. 
llega para partir de nuevo. No puede, sin embargo, prescindir de la creencia de que la nueva jornada es la jornada definitiva [...] Para el hombre, como sujeto de la historia, no existe sino su propia y personal realidad. No le interesa la lucha abstracta sino su lucha concretamente (Mariátegui, 1959, 23-24).

Por lo anterior queda claro que para Mariátegui la historia no puede ser comprendida desde la objetividad de las leyes sino más bien de la subjetividad del ideal. En este sentido, el concepto de mito juega un rol central. Este articula los elementos señalados y ofrece en su real dimensión lo que significa la historia para Mariátegui. En su apelación al mito se deja notar que la historia es la realización de un ideal: el socialismo. Esta implica ingresar a una lucha en el terreno de la cultura, enfrentar los valores sociales predominantes, y, por esto, tener la sensación de ir contra corriente. De este modo, el cambio histórico que implica el socialismo exige una férrea creencia, una fe en valores diferentes y en la posibilidad de un horizonte distinto. Pero, además, el mito del socialismo en Mariátegui pone en el centro al sujeto, ya que el sentido religioso que tiene no es transcendental, sino más bien apela a recuperar el mundo para los sujetos, superar la alienación de la sociedad capitalista. De este modo, realizar el cielo en la tierra.

Un aspecto central del concepto de mito es la agonía. El concepto es recogido del pensamiento del libro La agonía del cristianismo del pensador español Miguel de Unamuno. Mariátegui resalta la recuperación del significado griego del término: "agon" es lucha. El sentido de la lucha es de naturaleza subjetiva, consiste en mantener ideales en una situación adversa. De este modo, agoniza quien se ve enfrentado a un presente adverso en donde la espiritualidad ha perdido terreno dando paso a un mundo desencantado. Unamuno utiliza la agonía para dar cuenta de la experiencia del cristianismo pero Mariátegui para dar cuenta de adversidad de los ideales revolucionarios antes de la primera guerra mundial.

\footnotetext{
(...) El bienestar material, la potencia física de las urbes, habían generado un respeto supersticioso por la idea del Progreso. La humanidad parecía haber hallado una vía definitiva. (...)

No faltaban los hombres a quienes esta chata y cómoda filosofía no lograba seducir ni captar. Jorge Sorel, uno de los escritores más agudos de Francia prebélica, denunciaba por ejemplo las ilusiones del progreso. Don Miguel de Unamuno predicaba quijotismo. Pero la mayoría de los europeos había perdido el gusto por la aventura y de los mitos heroicos. (...) (Mariátegui, 1959, 14).
}

La posibilidad del cambio histórico está en la lucha agónica, es decir en confrontar una realidad que se muestra definitiva. La revitalización de esta lucha se dio después de la primera Guerra Mundial, cuando dos movimientos: el fascismo y el comunis-

\section{6/ REVIISTA de SOCIOLOGÍA 26}


mo muestran al mundo la fuerza del ideal. Ambos son movimientos de masas de creyentes pero existe una diferencia radical. El fascismo cree en la restauración del orden medieval, su horizonte es pasadista. El comunismo cree en la lucha final de la revolución social, su horizonte mira hacia el futuro. Dentro de la concepción histórica moderna el fascismo no tiene lugar, mientras el comunismo expresa su más alta realización. Mariátegui rescata el sentido de avance de la lucha final porque moviliza hacia algo aún no realizado que debe cumplirse, más allá de si se logra o no. En este sentido, el mito de la revolución social funciona como criterio normativo de la teleología moderna. Así pues, la agonía socialista es el genuino movimiento de los ideales modernos.

La revolución francesa tuvo la misma idea de su magnitud. Sus hombres creyeron inaugurar una nueva era. (...) La república individualista y jacobina aparecía como desiderátum de la humanidad. La revolución se sentía insuperable. Menos de un siglo y medio ha bastado para que este mito envejezca.

Sin embargo, la revolución proletaria es consecuencia de la revolución burguesa. [Ella] ha creado en una centuria las condiciones materiales y espirituales de un orden nuevo.

La ilusión de la lucha final resulta pues una ilusión muy antigua y muy moderna. Cada dos, tres o más siglos esta ilusión reaparece con distinto nombre. Y, como ahora, es siempre la realidad de una innumerable falange humana. Posee a los hombres para renovarlos. Es el motor de todos los progresos. Es la estrella de todos los renacimientos. (Mariátegui, 1959, 21-25)

La agonía del presente nos lleva al otro aspecto del mito en Mariátegui: la crítica de los valores. Este aspecto le da a su concepción histórica un carácter de revolución cultural y ética. Frente a los valores de una modernidad cientificista que desencanta el mundo y lo sujeta a las leyes de la ciencia, la crítica rescata la centralidad de la voluntad y la concibe como la fuerza que puede ir más allá de los límites establecidos por el fatalismo, y de este modo crear su propio destino. En este sentido, la revuelta cultural va contra a los valores de la sociedad apoyada en la ciencia. Ataca directamente el conformismo del presente que ha envuelto tanto a conservadores como socialistas al asumir la idea de progreso y al rechazar la violencia revolucionaria. La confianza en el desarrollo de las fuerzas productivas y los beneficios de la democracia eran la expresión de este conformismo, el cual, finalmente, sostenía el poder de los sindicatos y de los políticos dejando de lado el compromiso con la revolución.

La democracia conseguía el favor de las masas socialistas y sindicales, complacidas de sus fáciles conquistas graduales, orgullosas de sus cooperativas, de su organización, de sus casas del pueblo y sus burocracias. Los capitanes y los 
oradores de la lucha de clases gozaban de una popularidad, sin riesgos, que adormecía en sus almas toda veleidad revolucionaria. La burguesía se dejaba conducir por líderes inteligentes y progresistas que, persuadidos de la estolidez de una política de persecución de las ideas y de los hombres del proletariado, preferían una política dirigida a domesticarlos y ablandarlos con sagaces transacciones (Mariátegui, 1959, 14).

La reivindicación de la voluntad se expresa, además, en la afirmación del compromiso con la revolución social y con los valores que el socialismo encarna. La asimilación de estos habría sido mediada por su experiencia personal antes de su viaje a Europa. Ellos son: verdad, pureza, sinceridad, justicia e igualdad (Pinilla, 1995, 206-207). Asimismo, estos valores solo cobran sentido en el contexto de decidido compromiso con la revolución, es decir de la fe en el mito de la revolución social. De este modo la lucha revolucionaria solo se desarrollara si el proletariado aspira a un cambio en donde sus valores se realizaran. Según Mariátegui aquí radica el componente ético del marxismo, es decir en los valores que surgen a partir de la fe en la revolución, a partir del compromiso en la lucha final. A esto llama la moral de productores.

La función ética del socialismo [...] debe ser buscada [...] en la creación de una moral de productores por el propio proceso de la lucha anticapitalista. [...] La moral de productores no surge mecánicamente del interés económico, se forma en la lucha de clases, librada con ánimo heroico, con voluntad apasionada. Es absurdo buscar el sentimiento ético del socialismo en los sindicatos aburguesados [...] o en los grupos parlamentarios, espiritualmente asimilados al enemigo que combaten con discursos y emociones. (...)

El trabajador, indiferente a la lucha de clases, contento con su tenor de vida, satisfecho de su bienestar material, podrá llegar a una mediocre moral burguesa, pero no alcanzará jamás a elevarse a una ética socialista (Mariátegui, 1981, 57-60)

El mito en Mariátegui permite tener una comprensión cabal de lo que significa socialismo para nuestro autor. Socialismo consiste en una creación heroica, es decir la constitución de una realidad social a través de una lucha política inspirada por la fe revolucionaria. En efecto, sobre la base de lo sostenido hasta el momento, podemos afirmar que para Mariátegui no es posible el cambio social al margen de la lucha axiológica. Por esto, no es posible el socialismo si este no se concibe como un proyecto de revolución valorativa, creadora de nuevos valores sustentados en la fe de la revolución social.

\section{8/ REVISTA de SOCOLOOGíA 26}




\section{La historia marxista del Perú}

Los conceptos presentados son usados por Mariátegui para plantear su narrativa de la historia peruana. Desde sus supuestos, la historia no es la concreción de la ley de la naturaleza o expresión de su desarrollo, como sí lo era para positivistas y espiritualistas, sino más bien ella es la concreción de la acción de un sujeto histórico. Así pues, la política y los valores culturales aparecen como factores de cambio al lado de las características de las relaciones de producción, dándoles a nuestra formación social características definidas.

La debilidad del imperio español residió precisamente en su carácter y estructura de empresa militar y eclesiástica más que política y económica. En las colonias españolas no desembocaron como en las costas de Nueva Inglaterra grandes bandas de pioneer. A la américa Española no vinieron casi sino virreyes, cortesanos, aventureros, clérigos, doctores y soldados. No se formó por esto una verdadera fuerza de colonización. [...] El pioneer español carecía, además, de aptitud para crear fuerza de trabajo (Mariátegui, 1999, 14-16).

Desde esta perspectiva Mariátegui interviene en el debate sobre la nación peruana discutiendo las causas que explican su proceso histórico y las posibilidades de su porvenir. En primer lugar, rechaza la explicación positivistas que atribuía el problema de la nación a la diversidad de razas, pero también critica la explicación eminentemente moral de los espiritualistas. Para Mariátegui el problema central de la nación surgió con la conquista y se desarrolló a lo largo de la colonia. Este consistía en la incapacidad de los sectores dominantes de restablecer la unidad orgánica perdida, los vínculos comunitarios entre todos los grupos sociales existentes, con la caída y conquista del imperio de los incas, modelo de comunidad integrada. Ni los conquistadores, ni los gobiernos virreinales, y sobretodo, tampoco la república han podido realizar esta tarea. Esta incapacidad es de naturaleza estructural pero también valorativa. En efecto, las clases dominantes desarrollaron sus intereses económicos dentro de la fragmentación de la sociedad, por tanto, no les interesó formar un mercado interno y desarrollar una economía integrada a él; pero tampoco les importó asumir su rol dirigente en la sociedad, ya que sentían despreció hacia a las clases subordinadas, sobre todo a la indígena, y un sentimiento de extrañamiento o desconocimiento frente a ellas. Estos factores definían la debilidad de las clases dominantes y su dependencia del poder de las metrópolis. De este modo, Mariátegui puso sobre la mesa el problema de la formación de una clase dirigente.

Durante la república el problema de la nación puede resumirse en ¿cómo hacer partícipes de la república a las tres cuartas partes de la población, a saber la indígena? 
Conocido también como el problema del indio. Mariátegui plantea el problema en términos económico-sociales. A la vez, rechaza las tesis de que el indio no podía ser ciudadano a causa de su raza o moralidad. Afirma que el problema del indio es el problema de la tierra. Es decir, son las relaciones sociales de producción que se han constituido en la agricultura las que impiden al indio ejercer sus derechos políticos. Lo central de la exposición de Mariátegui es que a través del problema de la tierra caracteriza la formación social peruana, establece la estructura de clases y las relaciones sociales de producción, pero además, caracteriza las relaciones políticas que nacen de ellas. De este modo, le da un nuevo significado al término raza. Ahora, ella refiere a la posición social dentro de una estructura económica política capitalista dependiente. Así pues, las sociedades poscoloniales, dependientes y fragmentadas como la peruana se caracterizan por diferenciarse internamente a través de identidades raciales antes de usar identidades de clase. Esta tesis es central para cualquier proyecto socialista en el Perú y en América Latina.

Económica, social y políticamente, el problema de las razas, como el de la tierra, es en su base el de la liquidación de la feudalidad. (...)

En países como el Perú y Bolivia, y algo menos el Ecuador, donde la mayor parte de la población es indígena, la reivindicación del indio es la reivindicación popular y social dominante.

En estos países el factor raza se complica con el factor clase en forma que una política revolucionaria no puede dejar de tener en cuenta. (...)

El realismo de una política socialista segura y precisa en la apreciación y utilización de los hechos sobre los cuales le toca actuar en estos países, puede y debe convertir el factor raza en factor revolucionario (Mariátegui, 1969, 21-22 y 32-33).

Las posibilidades de cumplir la promesa republicana estaban necesariamente vinculadas a la superación de la fragmentación social encarnada en la fuerte diferenciación entre razas y en una estructura económica precapitalista y dependiente. Mariátegui encuentra esta posibilidad en la tradición indígena sobreviviente: el colectivismo o comunismo incaico. Según nuestro autor, esta tradición son los rezagos de lo que fue la única comunidad orgánica que tuvo el Perú: el imperio incaico. En ella el Estado supo controlar la fuerza del individualismo e imponer el deber social entre todos los miembros del imperio. De este modo, lo que surgió en el imperio fueron una economía y sociedad que brotó espontáneamente de los vínculos comunitarios. Las relaciones económicas satisfacían las necesidades de la comunidad, mientras las relaciones sociales se establecían entre miembros que se reconocían como pertenecientes a una misma comunidad. De este modo, el imperio de los incas aparecía como un modelo de nación. Sin embargo, esto no significó un llamado a volver al

\section{0/ REEUSTA DE SOCOOLOGÍA 26}


pasado. Al contrario, Mariátegui vio en la suma del mito del imperio de los incas y la tradición colectivista indígena, el instrumento de lucha contra la fragmentación social producida por el capital.

Para Mariátegui las luchas del indio por la tierra y la comunidad podían ser interpretadas como luchas anticapitalistas y, bajo la dirección política adecuada, socialistas, además de nacionalistas. Él operaba una síntesis entre valores colectivistas indígenas, mito incaico, y socialismo; porque entiende que el sentido de las luchas indígenas solo es posible dentro de un proyecto socialista que re-signifique la tradición colectivista y el mito incaico. De este modo, la adversa realidad de los indígenas y su posible victoria entran en el marco del provenir histórico, ya que se convierten en luchas contra las formas de acumulación de una economía dependiente y aspiran a construir una comunidad orgánica moderna inspirados por el mito de la revolución. En este proceso, el indio realiza la promesa de la república recuperando la única sustancia que le puede dar soporte: la tradición indígena. Así, Mariátegui hace del indio el sujeto moderno de la historia peruana.

El"nuevo indio" explica e ilustra el verdadero carácter del indigenismo que tiene en Valcárcel uno de sus más apasionados evangelistas. La fe en el resurgimiento indígena no proviene de un proceso de "occidentalización" material de la tierra keswa. No es la civilización, no es el alfabeto del blanco, lo que levanta el alma del indio. Es el mito, es la idea de la revolución socialista. La esperanza indígena es absolutamente revolucionaria. [...] La historia universal tiende hoy como nunca a regirse por el mismo cuadrante. ¿Por qué ha de ser el pueblo inkaiko, que construyó el más desarrollado y armónico sistema comunista, el único insensible a la emoción mundial? La consanguinidad del movimiento indigenista con las corrientes revolucionarias mundiales es demasiado evidente para que precise documentarla. Yo he dicho ya que he llegado al entendimiento y a la valoración justa de lo indígena por la vía del socialismo. El caso de Valcárcel demuestra lo exacto de mi experiencia personal. Hombre de diversa formación intelectual, influido por sus gustos tradicionalistas, orientado por distinto género de sugestiones y estudios, Valcárcel; resuelve políticamente su indigenismo en socialismo. En este libro nos dice, entre otras cosas, que "el proletariado indígena espera su Lenin". No sería diferente el lenguaje de un marxista.

La reivindicación indígena carece de concreción histórica mientras se mantiene en un plano filosófico o cultural. Para adquirirla - esto es para adquirir realidad, corporeidad - necesita convertirse en reivindicación económica y política. El socialismo nos ha enseñado a plantear el problema indígena en nuevos términos. Hemos dejado de considerarlo abstractamente como problema étnico o moral para reconocerlo concretamente como problema social, económico y político. $\mathrm{Y}$ entonces, lo hemos sentido, por primera vez, esclarecido y demarcado (Mariátegui, Prólogo a Tempestad en los Andes). 


\section{Referencias bibliográficas}

ÁvILA, R. Q. (2010). La razón racial. Clemente Palma y el racismo a fines del siglo XIX. Lima: Fondo Editorial de la Universidad Científica del Sur.

BALLón, J. C. (2011). La complicada historia del pensamiento peruano. Lima: Ediciones del Vicerrectorado Académico de la UNMSM.

MARIÁTEGUI, J. C. (1959). El alma matinal y otras estaciones del hombre de hoy. Lima: Amauta.

MARIÁTEGUI, J. C. (1969). Ideología y política. Lima: Amauta.

MARIÁTEGUI, J. C. (1981). Defensa del marxismo. Polémica revolucionaria. Lima: Amauta.

MARIÁTEGUI, J. C. (1999). 7 ensayos de interpretación de la realidad peruana. Lima: Amauta.

MARIÁtEGUI, J. C. (s.f.). Prólogo a tempestad en los Andes. Obtenido de Red Latina sin Fronteras: https://redlatinasinfronteras.wordpress.com/2014/08/09/mariategui-prologo-atempestad-en-los-andes/

MÉNDEZ, C. (2000). Incas sí, indios no. Apuntes para el estudio del nacionalismo criollo. Lima: IEP.

PINILLA, C. M. (1995). La agonía del cristianismo en Mariátegui. En E. C. Gonzalo Portocarrero, La aventura de Mariátegui. Nuevas perspectivas. Lima: Fondo Editorial de la Pontificia Universidad Católica del Perú.

QuIJANO, A. (2007). Prólogo José Carlos Mariátegui. Reencuentro y debate. En J. C. Mariátegui, 7 ensayos de interpretación de la realidad peruana (págs. IX-LXXXI). Caracas: Fundación Biblioteca Ayacucho.

RIVERA, V. S. (2012). Tradicionistas y maurrasianos Joséde la Riva-Agüero (1904-1919). Lima.

SANDERS, K. (1997). Nación y tradición. Cinco discursos sobre la nación peruana 1885-1930. Lima: Fondo Editorial de la PUCP FCE.

SAYÁn, R. C. (2003). Deustua y su opción por la libertad. Una alternativa en el Perú de principios de siglo XX. En A. Castro, Sociedad y filosofía en el Perú. Lima: Red para el desarrollo de las ciencias sociales.

THURNER, M. (2012). El nombre del abismo: meditaciones sobre la historia de la historia. Lima: IEP. 